\title{
Trophodynamics and diet overlap of small pelagic fish species in the Bay of Biscay
}

\author{
Eneko Bachiller ${ }^{1,2, *}$, Xabier Irigoien ${ }^{1,3}$ \\ ${ }^{1}$ Marine Research Division, AZTI Foundation, Herrera Kaia Portualdea, z/g 20110, Pasaia (Gipuzkoa), Spain \\ ${ }^{2}$ Present address: Pelagic Fish Research Group, Institute of Marine Research (IMR), PO Box 1870, Nordnes 33, 5817 Bergen, \\ Norway \\ ${ }^{3}$ Present address: King Abdullah University of Science and Technology (KAUST), Red Sea Research Center, \\ 23955-6900 Thuwal, Saudi Arabia
}

\begin{abstract}
Small pelagic fish are the link between planktonic production and higher trophic levels. Competition for resources may play a role in the population dynamics of species, some of them probably standing out from the others due to greater feeding success. It is therefore important to understand the trophic niche of species overlapping both spatially and temporally. In this study, we have investigated the diet, prey preference, trophic niche breadth and diet overlap of the 8 major small pelagic species (anchovy, sardine, sprat, Atlantic and Mediterranean horse mackerel, bogue, Atlantic mackerel and Atlantic chub mackerel) inhabiting the Bay of Biscay. Results indicate that all fish feed mainly on calanoid copepods, incorporating larger prey like euphausiids and decapods to complete their diet. Differences in ingested prey diversity seem to be more limited by the available zooplankton at sea than by a specific diet preference by fish species, resulting in an overall high diet overlap, especially within clupeids but also between clupeids and other (larger) predator species. Consumption estimations for different prey groups could therefore determine whether such a large diet overlap between small pelagic fish, together with spatial cooccurrence, results in competition or enhances the effects of intraguild predation, which is important in terms of an ecosystem approach to fisheries management.
\end{abstract}

KEY WORDS: Diet composition - Prey preference · Diet overlap · Small pelagic fish · Bay of Biscay

Resale or republication not permitted without written consent of the publisher

\section{INTRODUCTION}

Small pelagic fish play a key role in marine ecosystems as they are the link between planktonic production and higher trophic levels (Estes et al. 2011, Pikitch et al. 2014). Fluctuations in their biomasses have been often associated with ecosystem regime shifts governed by physical processes (Alheit et al. 2009), although the underlying mechanisms are often poorly understood. Some authors have related the changes in biomass of small pelagic fish with zooplankton availability, the latter being determined mainly by the hydrological conditions (van der Lingen et al. 2006). Other authors have hypothesized that biomass changes could be, at least partially, trophically mediated through inter- and intraspecific interactions (e.g. Irigoien \& De Roos 2011). As an example, intraguild predation, in the form of sardine predation on anchovy eggs, has been shown to account for up to $33 \%$ of the anchovy egg mortality in the Bay of Biscay (Bachiller et al. 2015). In contrast, the diet of small pelagic species in terms of prey size is more determined by the available planktonic prey sizes than by behaviour or morphology of the fish (Bachiller \& Irigoien 2013). Planktivorous fish may thus use all the available prey size range (e.g. mesoand macro-zooplankton), not excluding the smallest prey as they grow, but incorporating larger prey as 
they acquire the capability of catching them (Bachiller \& Irigoien 2013). Hence, the dietary plasticity and ability to switch between filter (non-selective) and particulate (selective) feeding (e.g. van der Lingen et al. 2006, Garrido et al. 2007, Nikolioudakis et al. 2014) allows planktivorous fish to efficiently exploit the planktonic food web (van der Lingen et al. 2009). Large organisms are energetically the most valuable for predators (Nikolioudakis et al. 2014). Therefore, mechanisms like feeding specialization and plankton species-dependent evasive behaviours can result in inter-specific differences in terms of feeding efficiency (Scharf et al. 2000). However, generally, diet studies are addressed in a single species approach. This approach allows estimations of ingestion and impact on zooplankton but does not provide information about other ecosystem interactions, such as competition, that can determine in part the shape of the community and distribution (Irigoien \& De Roos 2011, Utne et al. 2012).

Small pelagic species share the ecosystem in the Bay of Biscay, which is relatively rich in zooplankton due to the high primary production around the main river plumes (Gironde and Adour) and upwelling zones (shelf break and Cap Breton) (Albaina \& Irigoien 2007). However, different mechanisms of general transport depending on hydrographical features and seasonal changes in the area (Koutsikopoulos \& Le Cann 1996) lead to fluctuations in zooplankton biomass distribution (Irigoien et al. 2008). This fluctuation can furthermore determine optimum feeding areas for some of the planktivorous fish species (Bachiller et al. 2013).

Several studies have addressed the diet of economically relevant species from the Bay of Biscay area: anchovy Engraulis encrasicolus (Plounevez \& Champalbert 1999, Cotano et al. 2008, Bergeron 2009), sardine Sardina pilchardus (studies on larvae; Conway et al. 1994, Munuera Fernández \& González-Quirós 2006), Atlantic horse mackerel Trachurus trachurus (Olaso et al. 1999), Atlantic mackerel Scomber scombrus and Atlantic chub mackerel Scomber colias (Lucio 1997, Olaso et al. 2005). However, all these studies were conducted in a single species context without simultaneous comparison with other species and thus without determination of their spatial and/or temporal diet overlap.

The main aim of the present study was to analyze the diet composition and diet overlap of co-occurring small pelagic species in the Bay of Biscay. Accordingly, stomach contents of the 8 major small pelagic fish species were analyzed from samples collected in spring and autumn, during day- and nighttime, and in 3 different areas around the Bay of Biscay. Al- though this has been attempted in other large marine ecosystems (e.g. Langøy et al. 2012), this is to our knowledge the first study on small pelagic fish in the Bay of Biscay that assesses diet composition, prey preferences, diversity-based trophic niche breadth and diet overlap of several species caught at the same time. Moreover, it is certainly the first work obtaining an individual prey characterization from the diets of each sampled stomach separately, which allows a study of individual variability and a way to account for empty stomachs. In addition, the diets of closely related species such as horse mackerel (Atlantic horse mackerel T. trachurus and Mediterranean horse mackerel T. mediterraneus) and mackerel (Atlantic mackerel S. scombrus and Atlantic chub mackerel $S$. colias), as well as non-exploited species such as bogue Boops boops and sprat Sprattus sprattus are compared for the first time. This study provides useful information for future studies addressing potential trophic interactions between pelagic species sharing the ecosystem through food web models or multispecies assessments.

\section{MATERIALS AND METHODS}

Samples were collected at different times of the day and in different areas of the Bay of Biscay during 3 oceanographic surveys: BIOMAN08 (6 to 26 May 2008 on board R/V 'Emma Bardán'), PELACUS1008 (17 September to 16 October 2008 on board R/V 'Thalassa') and BIOMAN09 (5 to 25 May 2009 on board R/V 'Emma Bardán').

Zooplankton samples were collected in all stations of BIOMAN surveys immediately after the pelagic trawls with vertical hauls of $63 \mu \mathrm{m}$ and $150 \mu \mathrm{m}$ PAIROVET nets (Smith et al. 1985, Wiebe \& Benfield 2003). Samples were preserved immediately after collection with $\mathrm{pH} 7$ buffered formaldehyde $(4 \%)$ (Harris et al. 2000). The samples were then stained $\left(24 \mathrm{~h}\right.$ with $1 \mathrm{ml}$ Eosin $5 \mathrm{~g} \mathrm{l}^{-1}$ ) in the laboratory and digitized to obtain meso-zooplankton abundance using the ZooImage image analysis software (Bachiller et al. 2012).

Samples of anchovy Engraulis encrasicolus, sardine Sardina pilchardus, sprat Sprattus sprattus, Atlantic horse mackerel Trachurus trachurus, Mediterranean horse mackerel T. mediterraneus, bogue Boops boops, Atlantic mackerel Scomber scombrus and Atlantic chub mackerel Scomber colias were captured using pelagic trawls (Table 1, Fig. 1). Fishing trawls were made in the upper water column based on registrations from acoustic sampling (ICES 2011a,b). Trawls 
Table 1. Sample summary of spring and autumn periods, depending on the corresponding geographical areas and sampling time ranges. $\mathrm{N}$ is the number of samples (stomachs collected), $\mathrm{TL}_{\min }$ and $\mathrm{TL}_{\max }$ are the minimum and maximum length of fish $(\mathrm{mm})$ respectively. Note that in spring, there were no data available for T. trachurus and $S$. colias during daytime; in autumn, no $B$. boops sample was obtained, and all other predator species were caught during daytime

\begin{tabular}{|c|c|c|c|c|c|c|c|c|c|c|}
\hline \multirow[t]{2}{*}{ Species } & \multirow{2}{*}{$\begin{array}{l}\text { Sampling } \\
\text { time }\end{array}$} & \multicolumn{3}{|c|}{ Cantabrian area } & \multicolumn{3}{|c|}{ Adour-Arcachon area } & \multicolumn{3}{|c|}{ Gironde area } \\
\hline & & $\mathrm{N}$ & $\mathrm{TL}_{\min }$ & $\mathrm{TL}_{\max }$ & $\mathrm{N}$ & $\mathrm{TL}_{\min }$ & $\mathrm{TL}_{\max }$ & $\mathrm{N}$ & $\mathrm{TL}_{\min }$ & $\mathrm{TL}_{\max }$ \\
\hline \multicolumn{11}{|l|}{ Spring } \\
\hline \multirow[t]{2}{*}{ E. encrasicolus } & Day & & & & 10 & 106 & 144 & & & \\
\hline & Night & 30 & 147 & 193 & 20 & 133 & 180 & 30 & 96 & 178 \\
\hline \multirow[t]{2}{*}{ S. pilchardus } & Day & & & & 10 & 142 & 240 & 10 & 144 & 240 \\
\hline & Night & 30 & 165 & 244 & 20 & 161 & 220 & 30 & 120 & 240 \\
\hline \multirow[t]{2}{*}{ S. sprattus } & Day & & & & & & & 20 & 50 & 143 \\
\hline & Night & & & & & & & 30 & 89 & 115 \\
\hline \multirow[t]{2}{*}{ T. trachurus } & Day & & & & 14 & 105 & 288 & 10 & 110 & 135 \\
\hline & Night & 20 & 135 & 266 & 30 & 112 & 382 & 20 & 72 & 182 \\
\hline \multirow[t]{2}{*}{ T. mediterraneus } & Day & & & & & & & & & \\
\hline & Night & 20 & 237 & 363 & & & & 20 & 106 & 135 \\
\hline \multirow{2}{*}{ B. boops } & Day & & & & 10 & 172 & 253 & 10 & 209 & 331 \\
\hline & Night & 30 & 157 & 360 & 1 & 246 & 246 & 3 & 122 & 230 \\
\hline \multirow[t]{2}{*}{ S. scombrus } & Day & & & & 10 & 127 & 315 & 10 & 298 & 364 \\
\hline & Night & 27 & 204 & 398 & 21 & 196 & 419 & 11 & 190 & 365 \\
\hline \multirow[t]{2}{*}{ S. colias } & Day & & & & & & & & & \\
\hline & Night & 1 & 338 & 338 & 5 & 290 & 378 & & & \\
\hline \multicolumn{11}{|l|}{ Autumn } \\
\hline E. encrasicolus & Day & 10 & 65 & 94 & 10 & 104 & 121 & 10 & 111 & 149 \\
\hline S. pilchardus & Day & & & & 20 & 161 & 230 & 10 & 119 & 182 \\
\hline S. sprattus & Day & & & & & & & 10 & 11 & 118 \\
\hline T. trachurus & Day & & & & 30 & 82 & 290 & 20 & 98 & 174 \\
\hline T. mediterraneus & Day & 10 & 88 & 117 & & & & 5 & 251 & 275 \\
\hline B. boops & Day & & & & & & & & & \\
\hline S. scombrus & Day & & & & 20 & 157 & 321 & 20 & 184 & 356 \\
\hline S. colias & Day & & & & 13 & 156 & 340 & 10 & 174 & 372 \\
\hline
\end{tabular}

ranged from 5 to $30 \mathrm{~m}$ depth with the exception of a maximum fishing depth of $45 \mathrm{~m}$ (during PELACUS 1008). Fish sampling was carried out only in those stations where at least 2 of the 8 target predator species were present in the same haul. The percentage of cooccurrence of fish species in the hauls is presented in Table 2 . Ten randomly selected individual per species and station were sub-sampled for the analysis, whenever captured fish numbers permitted (Fig. 1, Table 1). A complementary station in spring 2008 with bogue was used to collect additional stomach samples (Fig. 1). Fish were sized and weighed and then preserved frozen. Stomachs were extracted in the laboratory, weighed and preserved in $\mathrm{pH} 7$ buffered formaldehyde $(4 \%)$ for later stomach content analysis.

A stereomicroscope (model NIKON SMZ 645) was used to identify stomach contents. Only material contained in the stomachs was considered, whereas the contents of the intestine and oesophagus were discarded to reduce bias caused by different rates of digestion and gut passage times or cod-end feeding (Hyslop 1980). During processing, stomach contents were carefully extracted, and all identifiable mesoand macro-zooplankton were counted and classified to the lowest possible taxonomic group. Broken parts of appendixes were excluded from the counting. In total, the following 26 prey groups were identified: Acartia spp., Candacia armata, Centropages spp., Temora spp., other calanoids, Corycaeus anglicus, Oncaea spp., other cyclopoids, Euterpina acutifrons, Microsetella spp., other harpacticoids, juvenile copepods, unidentified copepod remains, Euphausiacea ord., Decapoda ord., Mysida ord., Amphipoda ord., Cirripedia infracl., Cladocera infraord., unidentified crustacean remains, Gastropoda cl., Bivalvia cl., Appendicularia cl., fish eggs, Actinopterygii cl., and other prey. In the Malacostraca class, nauplii, larvae and adults were considered together. Since no adult fish was found in gut contents, Actinopterygii cl. corresponded to larvae and juveniles.

All stomachs were analysed individually, and subsampling was used only in stomachs with $>500$ prey individuals (Bachiller \& Irigoien 2013). Parasitic organisms found in stomachs (e.g. Trematoda larvae and Anisakis sp.) did not show any relationship either with total prey abundance in gut contents or with stomach fullness, so they were excluded from the diet analysis. 


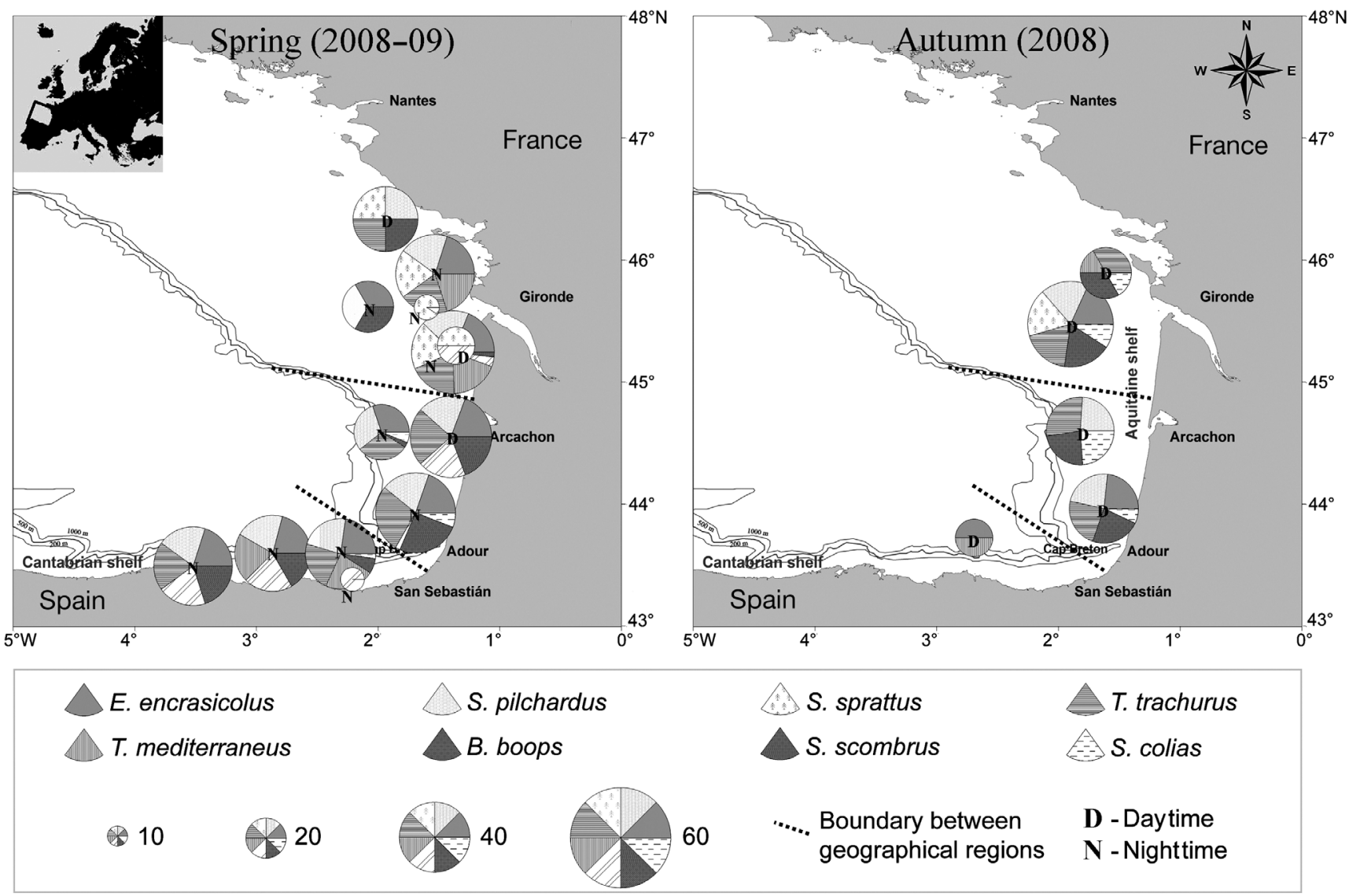

Fig. 1. Area of study and distribution of samples of the 8 major small pelagic fish species (Engraulis encrasicolus, Sardina pilchardus, Sprattus sprattus, Trachurus trachurus, T. mediterraneus, Boops boops, Scomber scombrus, Scomber colias) caught in BIOMAN (spring 2008 and 2009) and PELACUS (autumn 2008) surveys during day- and nighttime. Size of the circles is proportional to the total number of fish collected at each station. The lines denoting boundaries between geographical regions are drawn between the midpoints of stations belonging to different regions

\section{Data range definition}

Data collected from BIOMAN surveys corresponded to spring, whereas autumn season data were obtained from PELACUS1008 sampling (Fig. 1). Light regime for the region was considered for comparison between day and night catches. Accordingly, stations sampled between 08:00 and 19:00 h GMT were defined as 'daytime' catches and those between 21:00 and 06:00 h GMT as 'nighttime' catches. All pelagic trawls during PELACUS1008 survey (autumn) were made during daytime (Table 1). A categorization into 3 different geographical areas was also done considering the same boundaries as

Table 2. Spatial overlap of predator species in sampling stations. Data are presented as the percentage of co-occurrence in hauls. See Fig. 1 for full species names

\begin{tabular}{|lccccccc|}
\hline & S. pilchardus & S. sprattus & T. trachurus & T. mediterraneus & B. boops & S. scombrus & S. colias \\
\hline E. encrasicolus & 62.8 & 19.2 & 86.2 & 42.9 & 25.5 & 76.5 & 26 \\
S. pilchardus & $\mathrm{x}$ & 27 & 70.4 & 39.1 & 41 & 68.8 & 38.5 \\
S. sprattus & & $\mathrm{x}$ & 25.9 & 25 & 16.7 & 17.4 & 12.5 \\
T. trachurus & & & $\mathrm{x}$ & 42.9 & 40.7 & 78.6 & 48.2 \\
T. mediterraneus & & & & $\mathrm{x}$ & 33.3 & 28.6 & 31.9 \\
B. boops & & & & $\mathrm{x}$ & 34.6 \\
S. scombrus & & & & & & & \\
\end{tabular}


Bachiller \& Irigoien (2013): Cantabrian area (from Cap Breton westwards, within and off the Cantabrian shelf; Fig. 1), Adour-Arcachon area (within the Aquitaine shelf, in front of the Adour river plume and Arcachon, up to near $45^{\circ} \mathrm{N}$; Fig. 1) and Gironde area (Aquitaine shelf under the influence of the Gironde river plume, up to $46.5^{\circ} \mathrm{N}$; see Fig. 1). In addition, for some of the analyses, 130 and $230 \mathrm{~mm}$ were established as boundaries to separate small (<130 mm), medium (130 to $230 \mathrm{~mm}$ ) and large (>230 mm) predators (Bachiller \& Irigoien 2013).

\section{Diet analysis}

Although our analysis is based on both numerical and weight estimations, in order to assess the importance of prey groups in the diet, the contribution of a given prey as energetic input has to be considered (van der Lingen et al. 2009). Therefore, prey abundances and weights were considered in the description, but figures presented here are only those for the diet composition converted to prey biomass. Abundances of prey were used as qualitative descriptors (van der Lingen et al. 2009) to infer species richness, diversity index, trophic-niche breadth and prey selection index.

The diet composition was first explored using numerical and weight percentages of prey groups relative to total prey consumption. To determine the weight of each prey group, length-weight conversion equations were used based on literature. Average total length of prey species $(\mathrm{mm})$ was obtained from Bachiller \& Irigoien (2013), where direct length measurements were made for the first 50 prey items in each stomach. Since the stomachs used in that study were the same as those used in the present study, conversion of prey counts into biomass was made to the detailed species level (see Table S1 in the Supplement at www.int-res.com/articles/suppl/ m534p179_supp.pdf). Then, biomass calculations were merged to the species group level used in this analysis (i.e. 26 groups; Table S1). To exclude the effect of the sample size (number of fish per station) on the identified prey abundance, the biomass of each prey group was weighted by the number of fish per predator species and area or sampling time range. To ease later interpretation of the figures, prey groups were categorized into 12 groups: copepods merged by order (Calanoida, Cyclopoida and Harpacticoida) and copepod remains, Malacostraca with Euphausiacea and Decapoda orders as separated groups (including larvae and adults together in each of the groups), crustacean remains, molluscs, appendicularians, teleostei (Actinopterygii class, including all early life stages-eggs and larvae-since no adult was found in gut contents), and other prey (including the rest of the groups with a frequency in number $<5 \%$ of the total prey consumption). Results are presented as percentages of the total prey consumption for the 3 areas, considering the season and sampling time.

To analyze the diet in more detail, prey composition was then studied following the Costello (1990) graphical method but using prey weights instead of numbers. The relative frequency of occurrence (the percentage of non-empty stomachs in which a certain prey item occurred) was compared to the percentage of prey by biomass (the weight of a particular prey item as a proportion of the total weight of all prey items in the entire stomachs). The analysis was performed for the different areas depending on the season and sampling time ranges separately, for all predator species ranged by size. The lowest identified taxonomic level was represented in graphs, excluding prey groups with percentages of occurrence and weight $<20 \%$ to ease the interpretation of the figures. This graphical method provides a good description (Bacha \& Amara 2009) of prey importance as well as of predator feeding strategy (specialized or generalized) (see Costello 1990 for further details).

Feeding intensity was assessed using stomach filling degree calculations as a proxy. The stomach filling degree was defined as the sum of weights of all the prey in a stomach (mg) divided by the total length of fish (mm). This approach is considered to be a useful estimator of the feeding intensity that excludes the effect of the fish size and avoids subjectivity problems expected from visual stomach fullnessscaling methods such as the trophometer (Olaso et al. 1999) or the 1 to 5 scale of stomach fullness (IMR; Langøy et al. 2012).

Prey species richness $(S)$ was defined as the number of different prey groups found in gut contents. The diet diversity was expressed by the ShannonWiener diversity index $\left(H^{\prime}\right)$, calculated from the extended prey species list (i.e. 26 groups).

Prey selectivity was estimated using Ivlev's elec-

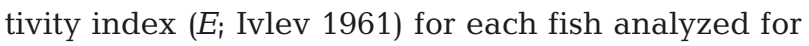
diet. Since plankton samples were obtained in BIOMAN surveys, only spring data were available to estimate the index. Further, since in these surveys only 3 stations were sampled during daytime (Fig. 1), only nighttime results are considered. The value of the index was therefore calculated only for the night 
data collected during spring, with the following equation:

$$
E=\frac{\left(r_{i}-p_{i}\right)}{r_{i}+p_{i}}
$$

where $r_{i}$ is the proportion of prey item $i$ in the fish stomach, and $p_{i}$ is the proportion of prey item $i$ available from the marine environment. The index has a possible range of -1 to +1 , with values close to -1 indicating avoidance or inaccessibility of the prey, values around zero indicating random selection from the environment and values close to +1 indicating active selection (Strauss 1979). $p_{i}$ estimations for the equation were made considering samples caught with both $63 \mu \mathrm{m}$ and $150 \mu \mathrm{m}$ plankton nets separately. However, non-parametric (Shapiro-Wilks test, p < $0.0001)$ comparisons showed that there was no difference between electivity indexes calculated based on any of the mesh sizes ( $U$ tests between $E$ in each of the predator species, $\mathrm{p}>0.05)$. Thus, only $E$ indexes considering $p_{i}$ estimated from $150 \mu \mathrm{m}$ plankton net samples are shown, presented by predator species (all areas and sampling time ranges together) ranged by size. According to the categorization of prey, some groups were merged in order to be comparable for both methods (i.e. image analysis vs. microscope analysis). Due to the low number of data available for such prey comparisons in case of T. mediterraneus and $S$. colias, electivity index results of these 2 species are not shown. In any case, selectivity indexes should be treated with caution since they could reflect biases in sampling methodology as well as in prey identification. For example, undersampling of small or large organisms by a net (due to the organisms passing through the mesh or escaping) will result in apparent positive selection even if the fish is eating them in proportion to their abundance. Therefore, proper estimation of the selectivity requires the use of a combination of different types of nets for different plankton types, which multiplies the number of samples to be analyzed.

Trophic niche breadth was examined as in Scharf et al. (2000) and Bachiller \& Irigoien (2013) but considering the ratio scale by determining changes in the range of Shannon-Wiener diversity index $\left(H^{\prime}\right)-$ instead of prey size - with increasing predator size. This way, diversity vs. predator size regression quantiles (90th and 10th) were generated to estimate the extremes of the ratio scale data for each predator species. Slope comparisons were made between upper and lower bounds, with significant differences indicating an increase (divergent slopes) or decrease (convergent slopes) in diversity-based trophic niche breadth with increasing predator size. The difference between predicted diversity values of upper and lower bound regressions at any given predator size represented the trophic niche breadth (Scharf et al. 2000, Bachiller \& Irigoien 2013). Average trophic niche breadth was also compared to average predator size to evaluate whether a general size-based trend was apparent.

To assess the overlap in resource use between the pelagic planktivorous species, Pianka's index of niche overlap was applied:

$$
O=\frac{\sum p_{i, j} p_{i, k}}{\left[\left(\sum p_{i, j}^{2}\right)\left(\sum p_{i, k}^{2}\right)\right]^{1 / 2}}
$$

where $O$ is the overlap index between the 2 species $j$ and $k$ expressed as a value between 0 and 1 , and $p_{i, j}$ and $p_{i, k}$ are the proportions of the $i^{\text {th }}$ prey group in the diets of species $j$ and $k$, respectively. A value of 0 means no overlap and 1 indicates complete overlap in the diet. Comparison of diet overlap was done separately for both seasons and both sampling time ranges, in each of the geographical areas. The diet data come from stations where $\geq 2$ fish species were caught together, and the same number of individuals per species was sampled whenever the catch permitted. Therefore, $j$ and $k$ parameters in the equation were calculated as the percentage in weight of the consumption of each prey group with respect to the total prey consumption by all fish in a certain sample set, i.e. species and area or sampling time. To test for significance, the proportion of a given prey group in a given diet was randomized according to the Randomization Algorithm (RA2) of Lawlor (1980) and iterated 1000 times for each comparison of diet overlap using EcoSim Professional v.1.2d (Entsminger 2014). Lawlor (1980) described 4 randomization algorithms (RA1 to RA4) for niche overlap in which the zero states (the empty prey groups) and the niche breadth (the degree of utilization of a prey group) can be either relaxed or retained. Under RA2, the zero states are retained (i.e. empty prey groups from the stomach samples remain empty in the simulations), whereas niche breadth is relaxed (i.e. the proportion in the diet of each non-empty prey group is replaced by a uniform value between 0 and 1 ). In this study, the RA2 was considered to give the most realistic reflection of the Bay of Biscay pelagic system because some of the prey groups would be unavailable to fish in certain areas due to the patchy distribution of the plankton prey, whereas none of the fish species were assumed to have constraints on the utilization of the prey groups that were actually present. For example, Actinopterygii (fish larvae and juve- 
niles) can be available for all the fish in a certain area but are not potential prey for the smallest fish sizes, whereas large mackerel may contain all the prey groups (i.e. including the smallest prey) in their gut contents.

The statistical analyses and visualization were conducted using R v.3.0.2 (R Development Core Team 2014) and ggplot2 v.1.0.0 (Wickham 2009).

\section{RESULTS}

We used logistic multinomial regression models (iterated 2500 times) to evaluate variables affecting the diet composition in terms of biomass of different prey groups of all the fish. Fish species, total length of fish (mm), geographical area (Cantabrian area, Adour-Arcachon area or Gironde area), season (spring or autumn) and sampling time (day or night) were used as explanatory variables (see 'Materials and methods' for details on data range definition), whereas the prey weight composition was used as the response. Akaike's information criterion (AIC) tests showed that in addition to the total length (standardized null model, $\mathrm{AIC}_{\mu}$ 418357), the consecutive incorporation of the variables 'predator species' $\left(\mathrm{AIC}_{\mu+\text { species }}\right.$ 320702), 'geographical area' $\left(\mathrm{AIC}_{\mu+\text { speciestarea }} 262568\right)$, 'season' ( $\mathrm{AIC}_{\mu+\text { species+area+season }}$ 253166) and 'sampling time' $\left(\mathrm{AIC}_{\mu+\text { species+area+season+ }}\right.$ sampling time 249239) resulted in the last option as the most parsimonious model.

According to that, the following diet description analysis was made for each species (ranged by size for detailed description) grouped by (1) season and area and by (2) season and sampling time (note that all samples caught during autumn season were day catches; Fig. 1).

\section{Diet composition of small pelagic fish}

Percentages of occurrence, relative frequency in numbers and percentages of weight of preys found in stomachs of the small pelagic species ranged by size and separated by the geographical area, season and sampling time are presented as supplementary material (see Table S2 in the Supplement at www.intres.com/articles/suppl/m534p179_supp.pdf).

The variability in the diet was as large between areas and sampling time ranges as it was between species and fish size ranges (Figs. 2 \& 3, Table S2).

Clupeids showed a calanoid copepod-based diet composition, Centropages spp. and Temora spp. ap- pearing generally as the main copepod species both in terms of abundance and biomass in the diets. However, anchovy could incorporate larger prey to their diet (euphausiids and decapods) than could sardine and sprat at any season, area or time. Fish eggs were energetically important for the diet of the 3 species (especially for $>130 \mathrm{~mm}$ sardine). In addition, sardine could also feed on other prey like decapods and appendicularians, the latter being common but less important in terms of energy input (Figs. $2 \& 3$, Table S2).

Horse mackerel species, bogue and mackerel species showed a more diverse diet composition (Fig. 2). Small fish mainly ingested calanoid copepods (mostly Centropages spp. and Temora spp.), whereas $>130 \mathrm{~mm}$ predators obtained the most part of the ingested biomass from larger prey such as euphausiids, decapods and amphipods (Fig. 3, Table S2).

Euphausiids were the most important prey group in the diet of Atlantic and Mediterranean horse mackerel at any time and area (including the smallest fish size range). However, in some cases, calanoid copepods remained as the basis of their diet composition, such as for Atlantic horse mackerel in the Cantabrian area in spring (Figs. 2 \& 3, Table S2).

Bogue showed differences in the diet composition between fish size ranges, areas and time. Although euphausiids and amphipods had a significant contribution to the total ingested biomass in the Cantabrian area (at nighttime) and the Gironde (at daytime) respectively (Fig. 2), only amphipods were ingested frequently (Fig. 3). Other important prey groups were appendicularians (especially in the Adour-Arcachon and Gironde areas), fish larvae (especially for the largest bogue), and calanoid and poecilostomatoid (Corycaeus anglicus) copepods (Figs. 2 \& 3, Table S2).

Atlantic mackerel showed calanoid copepods as the main source of energy in the Gironde area, although for $>130 \mathrm{~mm}$ Atlantic mackerel, most of the biomass was obtained from large prey like euphausiids and fish eggs (e.g. during nighttime; Fig. 3). Euphausiids and fish eggs were also the main biomass input in the Cantabrian area. In the AdourArcachon area, the smallest fish fed mainly on calanoids, whereas for larger fish, decapods, fish larvae and other prey were more important (Figs. $2 \& 3$ ). Similarly, Atlantic chub mackerel also fed primarily on copepods in the Gironde area, although mysids, relatively low in numbers, contributed to their ingested biomass more than to the diet of the other species. Further, in the Adour-Arcachon area, where the importance of copepods was low, mysids seemed to 


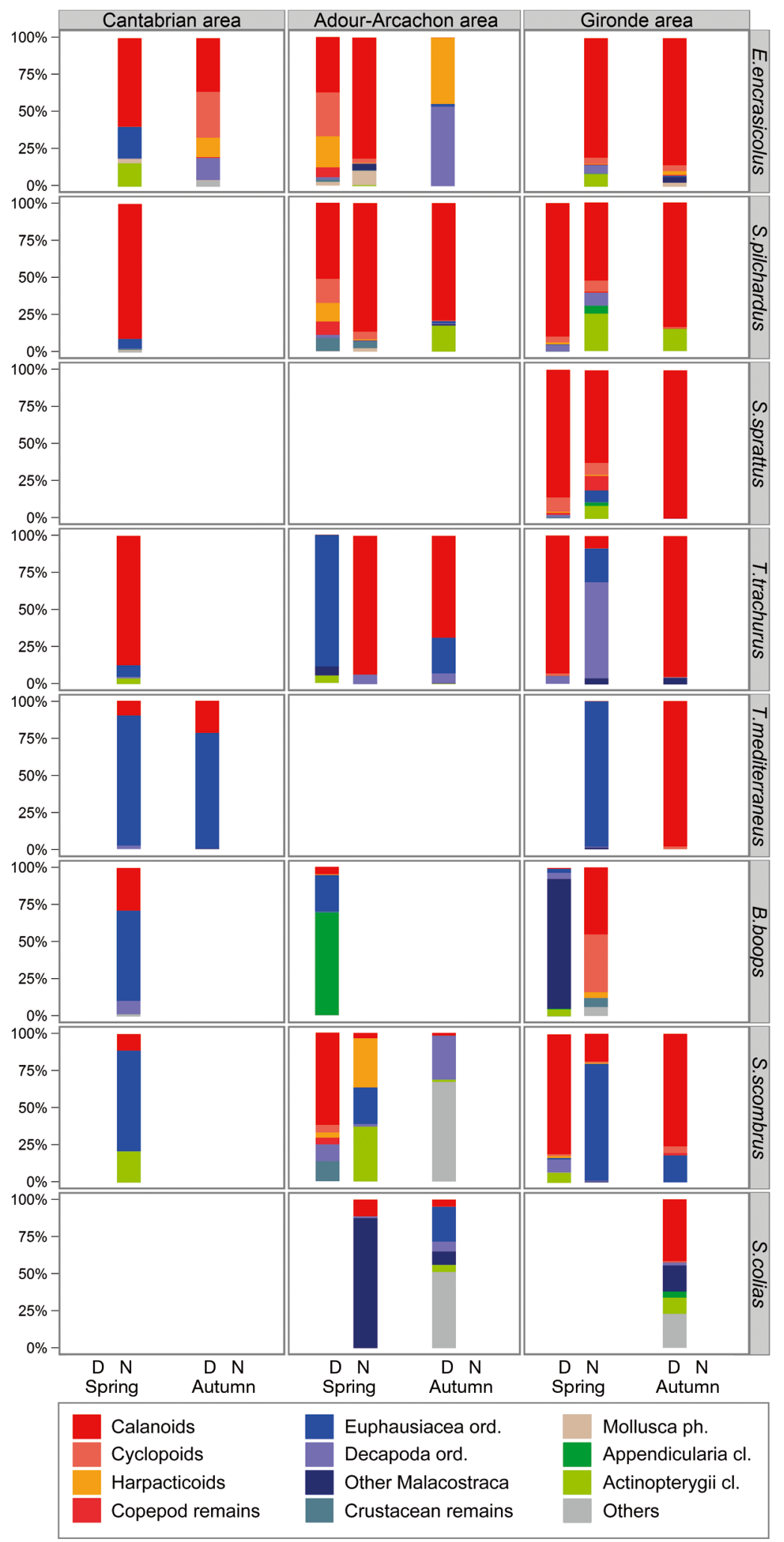

Fig. 2. Prey group composition (percentage of mean prey weight per stomach) in the diet of small pelagic fish species averaged over areas, seasons and sampling time. D and $\mathrm{N}$ are day and night sampling time, respectively. See Fig. 1 for full species names be the most important prey group in the diet composition for Atlantic chub mackerel diet (Figs. 2 \& 3, Table S2).

In general, copepods showed the highest numbers in stomach contents of all predator species. In spring and nighttime (when prey selection analysis was made), positively selected copepod species (e.g. calanoids Centropages spp. and Temora spp., poecilostomatoid $C$. anglicus and harpacticoid Microsetella spp.) also showed high numbers in the diet composition of small pelagic species (Fig. 4). Moreover, in those copepod species showing different abundances between areas, fish species and/or size ranges, the selection index also changed. For example, $C$. anglicus was frequent based on numbers $(33.33 \%)$ and occurrence $(100 \%)$ in $<130 \mathrm{~mm}$ bogue (Gironde area, nighttime), with an important contribution $(24.80 \%)$ to the total biomass (Fig. 3, Table S2), and they were positively selected by the smallest bogue (Fig. 4). In contrast, this prey species appeared as positively selected by medium-sized sardine (Fig. 4), but that was not reflected in the diet composition in terms of biomass (Fig. 3) since most of the biomass came from positively selected fish eggs (in all sardine) and appendicularians (in $<130 \mathrm{~mm}$ sardine). The same could be said about the Adour Arcachon area where, instead of copepods, other (larger) groups were more frequently ingested by all predators in comparison to other areas (Table S2). However, such a spatial difference was not reflected in terms of biomass input (Figs. $2 \& 3$ ) because large prey contributed to the ingested biomass more than copepods at any area. Therefore, positively selected copepods (Fig. 4) appeared as dominant prey only in cases where large prey ingestion was not detected (Figs. 2 \& 3). Regarding large prey, for example, large horse mackerel and mackerel showed positive selection upon euphausiids, and bogue showed preference on other prey like appendicularians (Fig. 4); all these prey were identified as energetically valuable in their corresponding species' diet composition (Figs. 2 \& 3). 

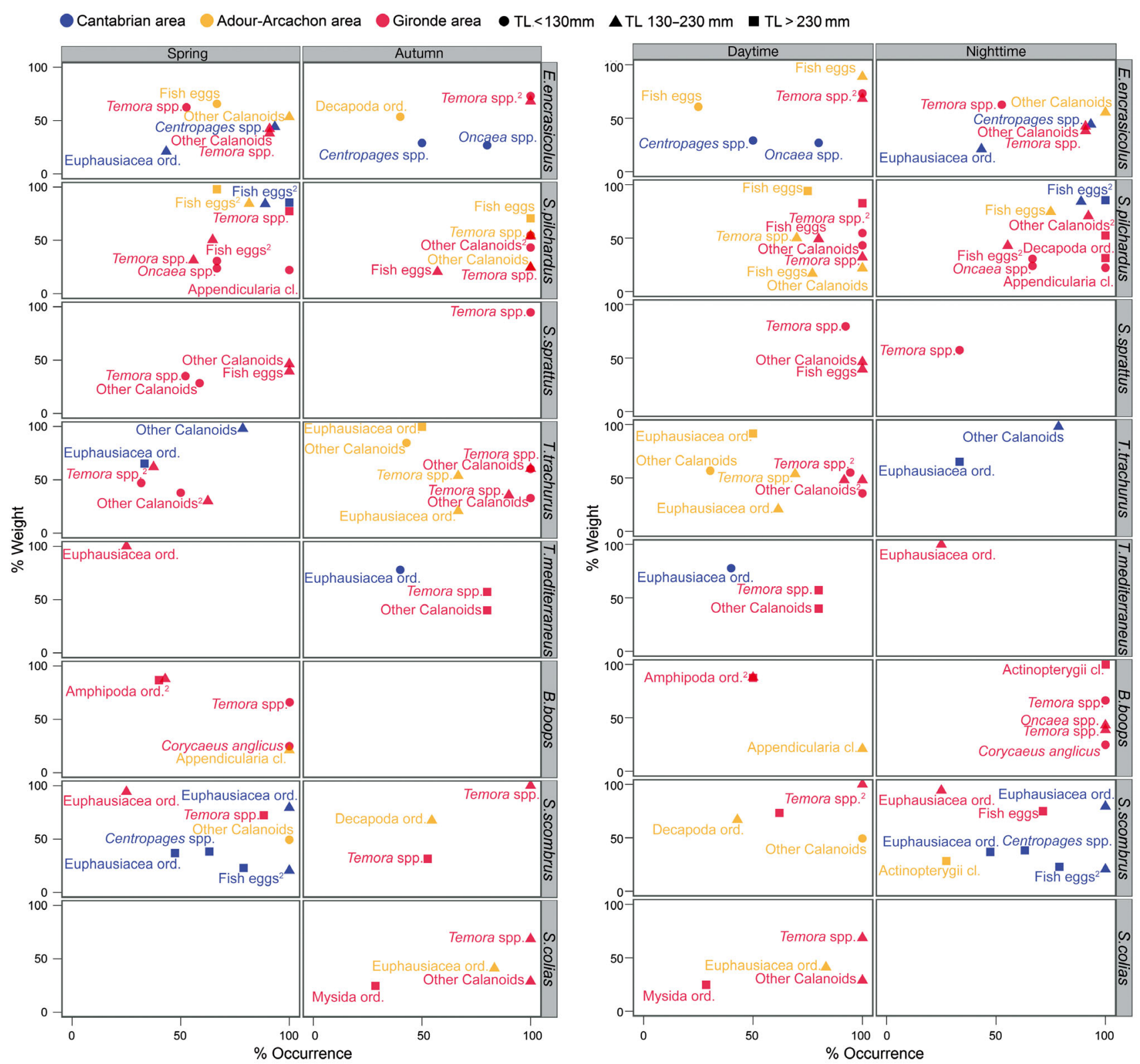

Fig. 3. Graphical representation of dominant prey for each predator species ranged by size according to Costello (1990), presented by areas and seasons (left) and by areas and sampling time (right). \% Occurrence is the relative frequency of occurrence of a certain prey item in stomachs, whereas \% Weight is the percentage weight of the specific group relative to the total weight of all prey found in the stomach. Point shapes correspond to the size ranges of predators, and prey labels are colored by geographical area. Labels with superscript numbers indicate that the same label defines such a number of the closest point shapes represented with the same color. See Fig. 1 for full species names

\section{Feeding intensity and feeding incidence}

The individual variability of the stomach-filling degree was high between all the species, areas and times. Moreover, differences between areas and times were greater than between the species within each case (Fig. 5). Overall, clupeids seemed to show a lower range of individual variability in stomach- filling degree than horse mackerel, bogue and mackerel. Except for anchovy, the rest of the species showed lower values during nighttime in all the areas. There was no clear seasonal trend in the stomach-filling degree, and values changed depending on both the areas and species (Fig. 5).

Atlantic and Mediterranean horse mackerel showed a higher number of empty stomachs than the other 

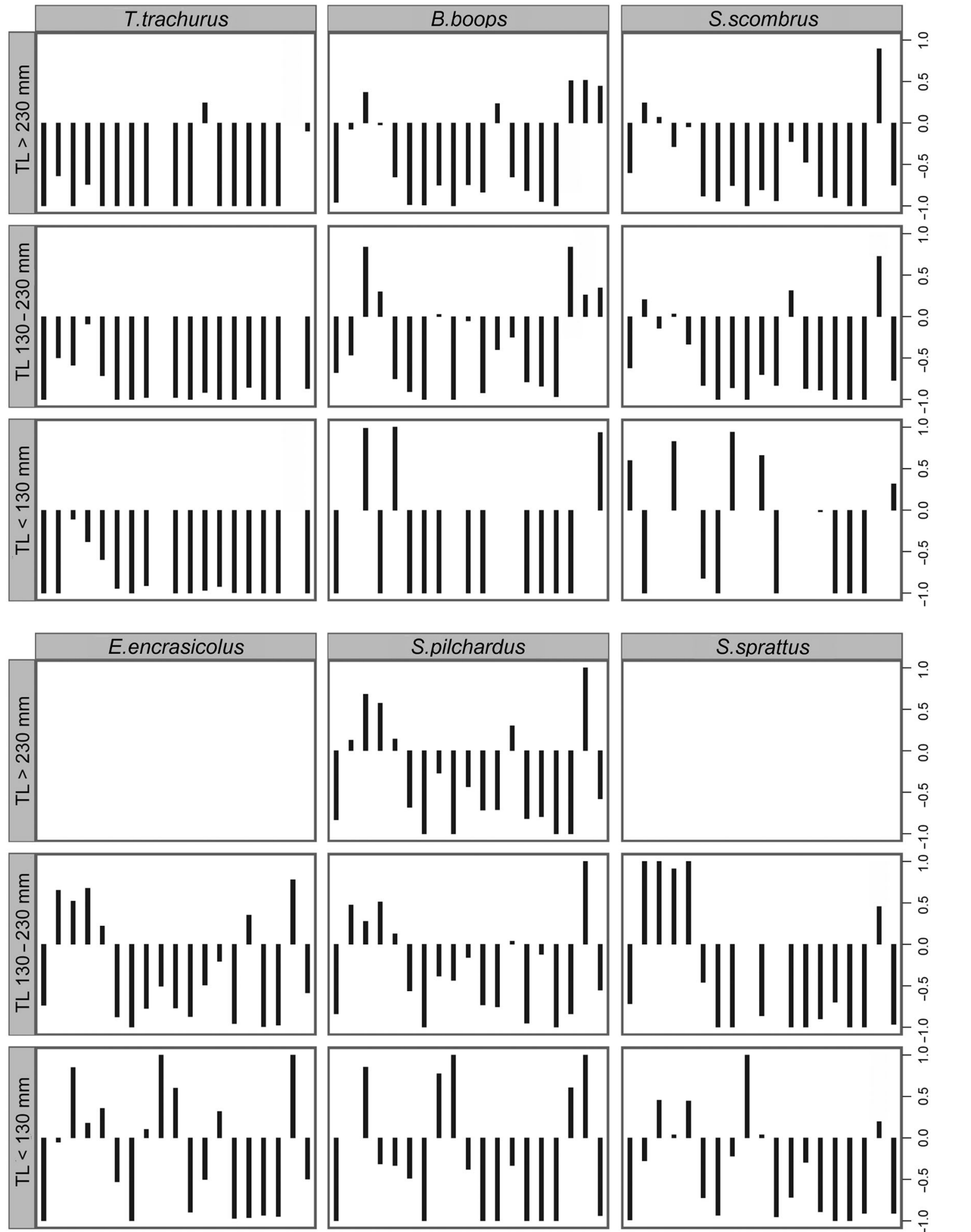

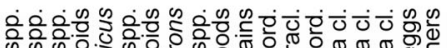

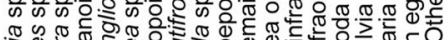

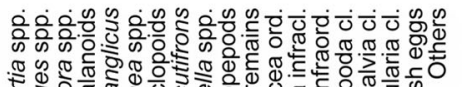

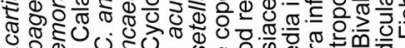

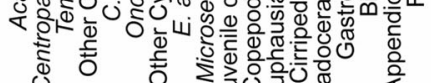
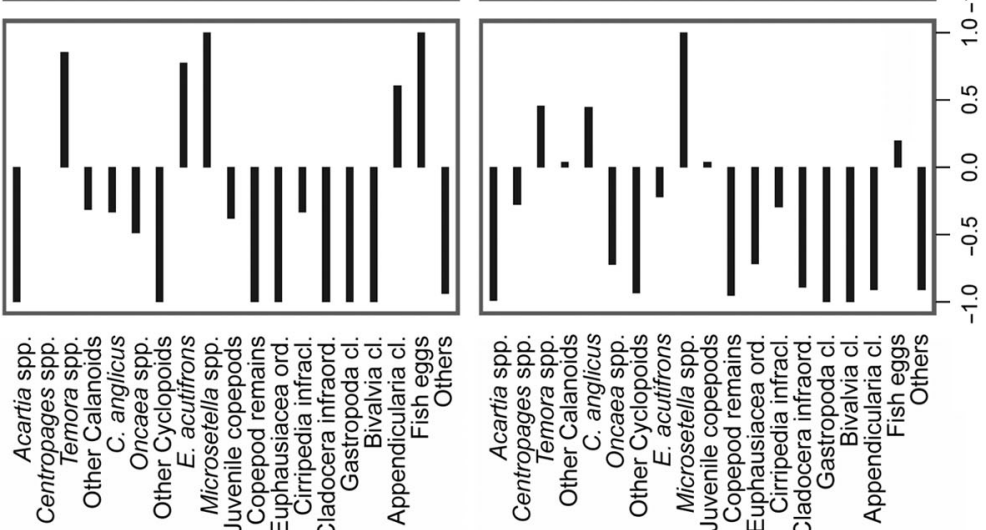

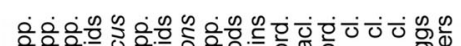

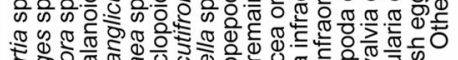

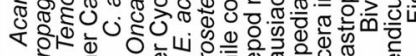

o

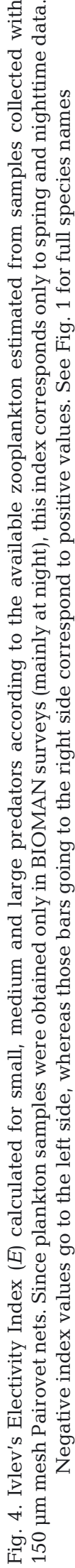




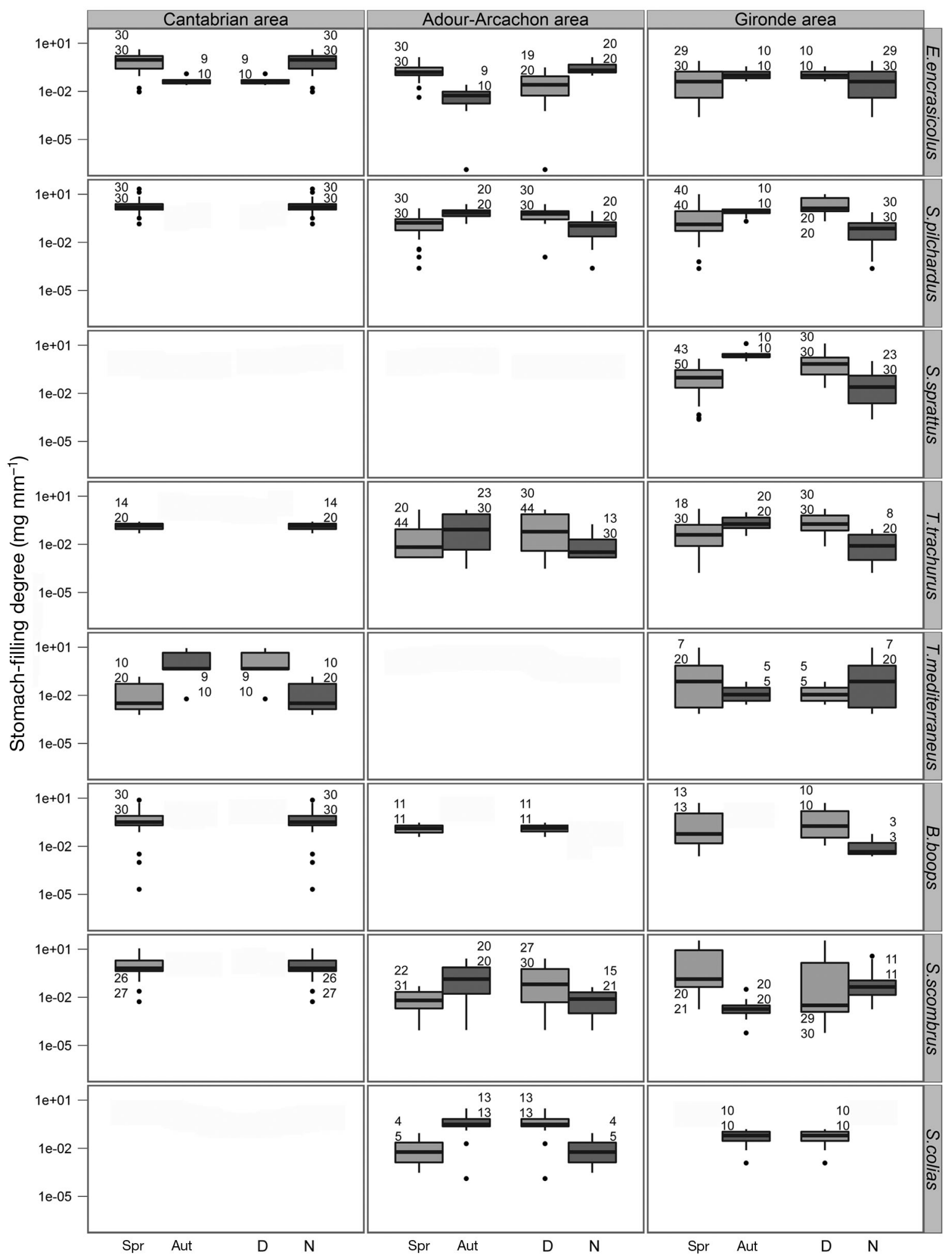

Fig. 5. Stomach-filling degree $\left(\mathrm{mg} \mathrm{mm}^{-1}\right)$ for different areas and species, depending on seasons (left side) and sampling time (right side). Horizontal lines indicate medians, the boxes extend to the 25 and 75 percentiles respectively, and the whiskers extend to the $5 \%$ and $95 \%$ quantiles. The number of non-empty stomachs is denoted next to the boxes (upper number) for each case together with the total number of stomachs sampled (lower number). Note the logarithmic scale of the vertical axis.

Spr: spring; Aut: autumn; D: daytime; N: nighttime 


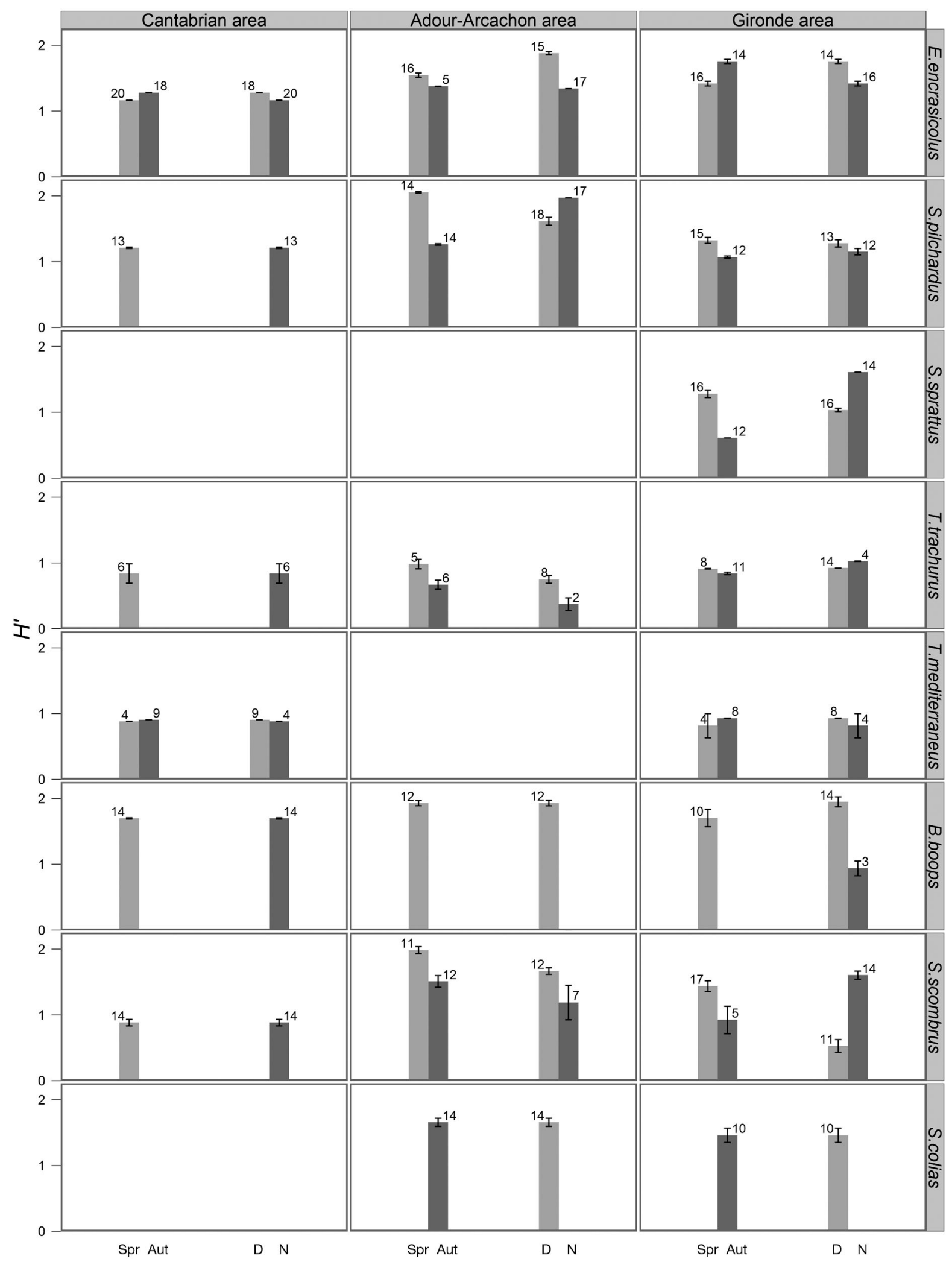

Fig. 6. Mean Shannon-Wiener diversity index $\left(H^{\prime}\right)$ for different areas and species, depending on seasons (left side) and sampling time (right side), with standard error bars. Numbers on the top of the bars are the mean species richness $(S)$. Spr: spring; Aut: autumn; D: daytime; N: nighttime 
species, in some cases their feeding incidence being $<50 \%$ (Fig. 5). The rest of the species showed a percentage of empty stomachs below $25 \%$ (Fig. 5).

\section{Species richness, diversity index and diversity- based trophic niche breadth}

Although in general, stomach contents from predator species caught in Adour-Arcachon area seemed to present higher Shannon Wiener diversity index values than those from other areas, variability in the diversity as well as species richness was as large between areas, seasons and sampling time as it was between species. Obviously, high diversity $\left(H^{\prime}\right)$ values corresponded to high richness (S) values (Fig. 6).

Anchovy and sprat increased significantly the Shannon-Wiener diversity-based trophic niche breadth with increasing body size, whereas Atlantic horse mackerel, bogue and Atlantic mackerel showed a decrease of the niche breadth at larger sizes (Fig. 7). In any case, no significant relation (trophic niche breadth $=1.24 \times$ mean predator length $\left.9.25 \times 10^{-5} ; R^{2}<0.01 ; \mathrm{p}=0.96\right)$ was observed in the mean trophic niche breadth with increasing predator size.

\section{Diet overlap}

\section{Cantabrian area}

In this area, all the comparisons made in spring and autumn corresponded to night and daytime ranges, respectively, and a single comparison could be made for autumn daytime samples. In spring at nighttime, the diet overlap was high $(O>0.60)$ between all small pelagic species. Mediterranean horse mackerel showed the maximum significant Pianka indices when comparing the diet to the other species. Anchovy was the species showing most of the nonsignificant overlap values in paired comparisons to the other species (Fig. 8).

In general, overlap indexes observed in the Cantabrian area were higher than those found in the Adour-Arcachon and Gironde areas (Fig. 8).

\section{Adour-Arcachon area}

Diet overlap occurred within clupeids (anchovy and sardine) and between clupeids and most of the other predator species, observations being signifi- cant at any season (Fig. 8, left side) and sampling time range (Fig. 8, right side). According to the season, anchovy showed the maximum significant overlap index values compared to sardine and Atlantic chub mackerel in spring $(O=0.68)$ and autumn $(O=$ 0.75), respectively (Fig. 8, left side). In addition, Atlantic horse mackerel and both mackerel species showed similar diet composition in autumn, with higher overlap indices observed when comparing horse mackerel to the Atlantic chub mackerel (Fig. 8, left side). High overlap was also observed between the Atlantic horse mackerel and Atlantic chub mackerel during daytime, whereas at night, Atlantic horse mackerel showed greater diet overlap with clupeids than with the other species (Fig. 8, right side).

\section{Gironde area}

During spring, high diet overlap occurred between clupeids, but the overlap index was significant only when comparing anchovy and sprat. However, in this analysis, paired comparisons showed high variability; for example, (1) the diet of horse mackerel species overlapped with that of clupeids (e.g. maximum $O=0.81$ between Mediterranean horse mackerel, sardine and sprat), but in those cases, values were not significant; (2) anchovy and bogue as well as sprat and Atlantic horse mackerel showed significant overlap values between them, but in contrast, the overlap between Atlantic horse mackerel and Mediterranean horse mackerel or bogue was low. In autumn, most of the comparisons showed nonsignificant values, with the exception of Atlantic mackerel which showed significant diet overlap with the rest of the species although values were relatively low (Fig. 8, left side).

The diet overlap was generally higher between the species during the day than at night. During daytime, not only clupeids overlapped in diet significantly but also other species like Mediterranean horse mackerel and Atlantic mackerel showed high diet overlap with sprat. Mediterranean horse mackerel and Atlantic mackerel also overlapped in diet, as well as the Atlantic horse mackerel, although significant values were obtained only in some cases. At night, the diet of clupeids overlapped with all the other species, but values were significant only between sprat and the other 2 clupeid species. The 2 horse mackerel species and the 2 mackerel species also showed high diet overlap between the species. In contrast, a low overlap index was observed for the Atlantic mackerel compared to bogue and sprat (Fig. 8, right side). 


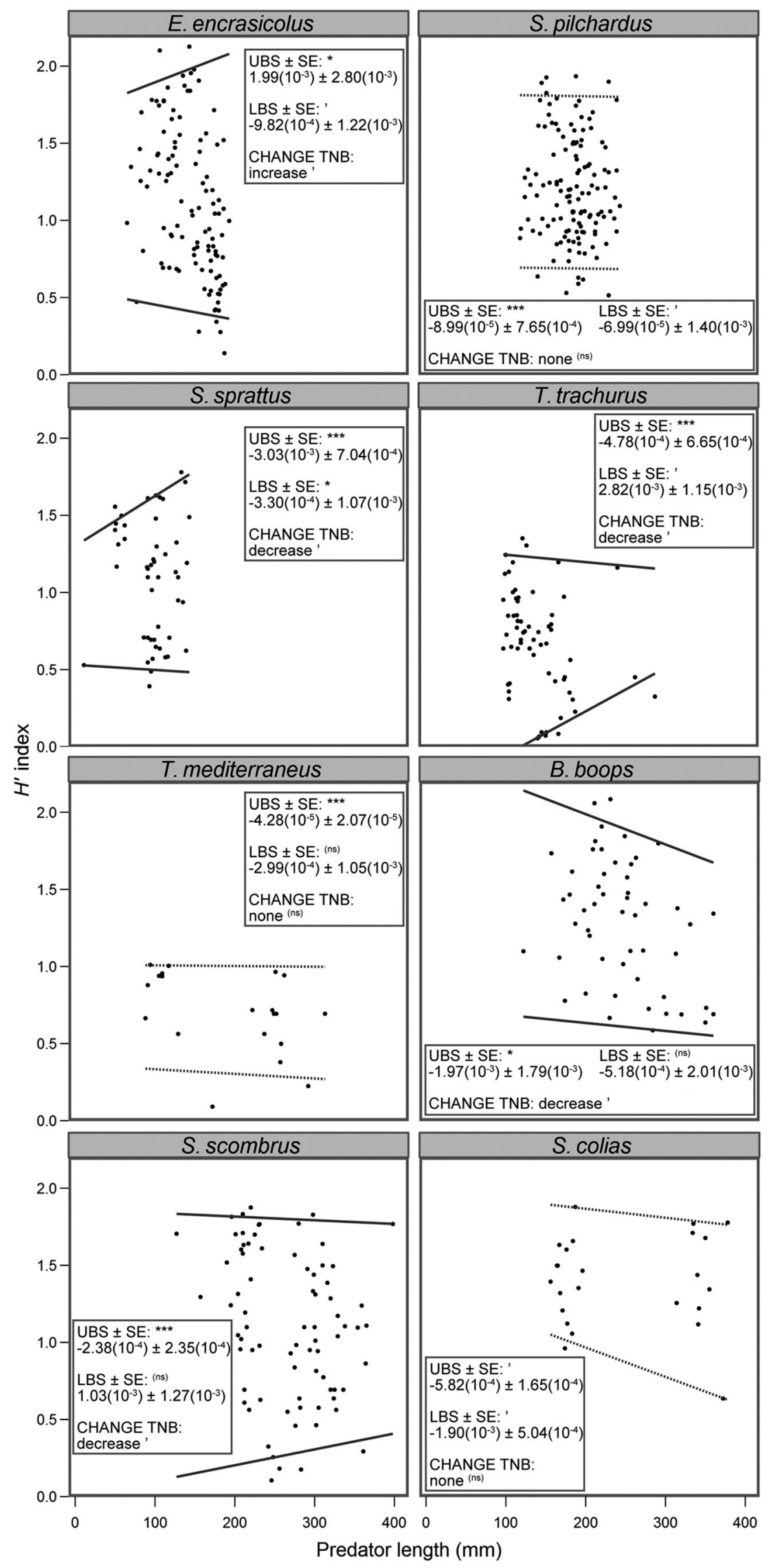

\section{DISCUSSION}

\section{Methodological aspects}

In this study, stomach contents were based on meso- and macro-zooplankton counts. However, for example, in the case of sardine, previous studies of their diet have shown that large numbers of phytoplankton (Garrido et al. 2008, Nikolioudakis et al. 2012, Costalago \& Palomera 2014) and microzooplankton (Varela et al. 1988, 1990) can be ingested depending on the area and food availability. Consequently, in our results, the relevance of the ingestion of the smallest fractions by small pelagic species could have been underestimated, especially when abundances of prey are used as qualitative descriptors (van der Lingen et al. 2009) to infer aspects such as species diversity index or trophic-niche breadth. However, to assess the importance of prey groups in the diet, the contribution of a given prey as energetic input has to be considered (van der Lingen et al. 2009) and it has been shown that even in areas with high phytoplankton concentrations, phytoplankton contribution to the ingested biomass is low compared to that of zooplankton and larger prey

Fig. 7. Scatter diagrams illustrating ShannonWiener diversity index $\left(H^{\prime}\right)$ as a function of predator length for each predator species. Each point represents the diversity in the stomach content of a single fish. Divergent or convergent quantile regression lines (solid lines) illustrate ontogenetic changes in the range of diversities with increasing predator size. Dotted lines represent non-significant change in trophic niche breadth. Results from quantile regressions of diversity vs. predator length comparisons are also presented. UBS: upper bound slope, from the quantile regression estimating $90^{\text {th }}$ (upper) quantiles of the comparison; LBS: lower bound slope, from the quantile regression estimating $10^{\text {th }}$ (lower) quantiles of the comparison. SE is the standard error of each quantile regression. CHANGE TNB represents decreases or increases in trophic niche width based on statistically significant differences between UBS and LBS. ${ }^{* * *} \mathrm{p}<0.0001,{ }^{* *} \mathrm{p}<0.001,{ }^{*} \mathrm{p}<0.01$, ' $\mathrm{p}<0.1$, (ns) not significant 


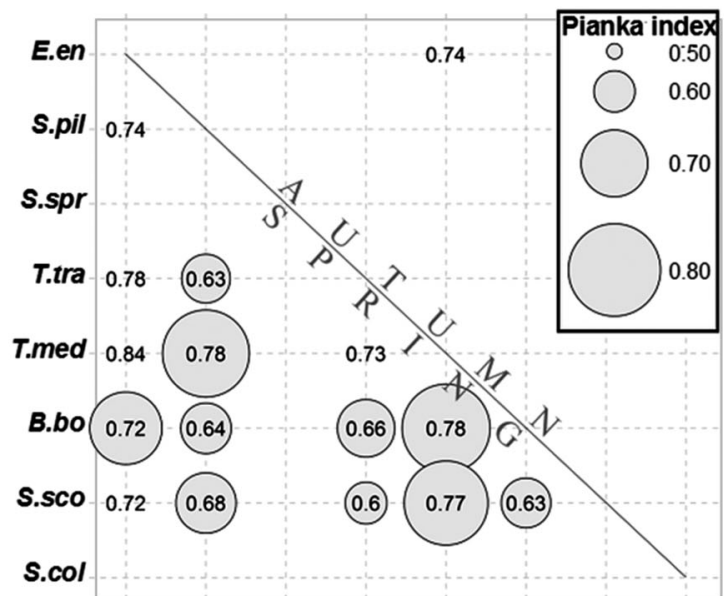

E.en S.pil S.spr T.tra T.med B.bo S.sco S.col

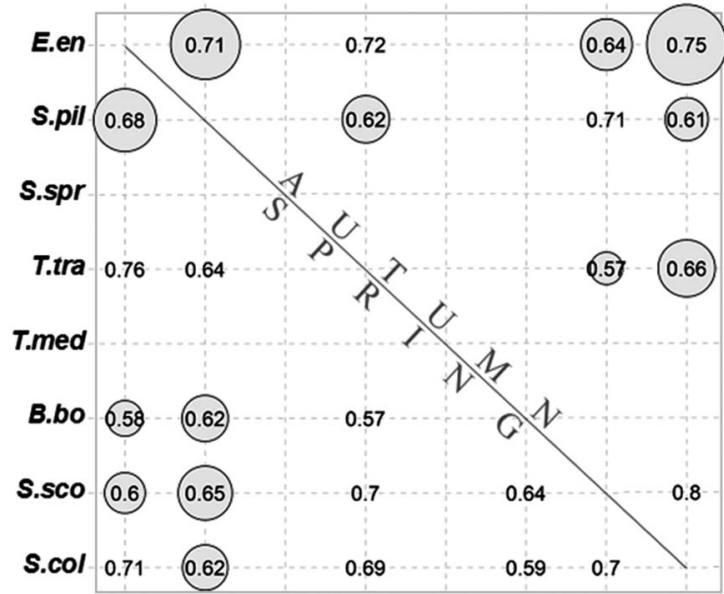

E.en S.pil S.spr T.tra T.med B.bo S.sco S.col

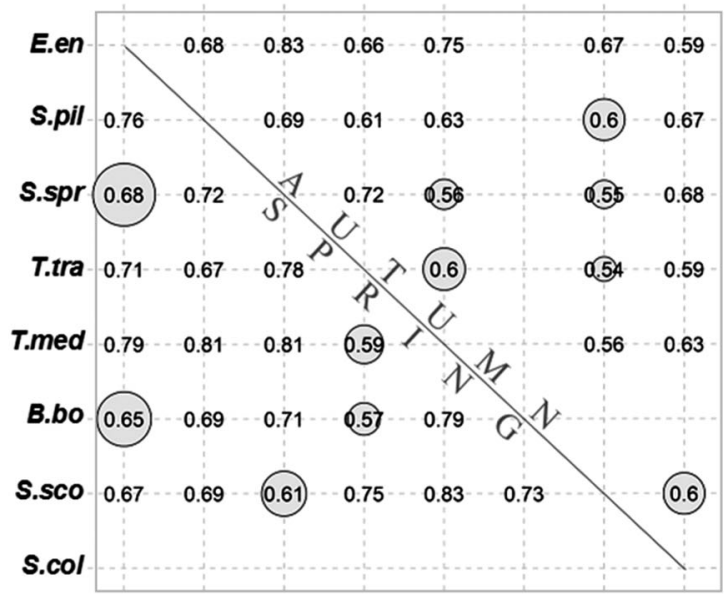

E.en S.pil S.spr T.tra T.med B.bo S.sco S.col
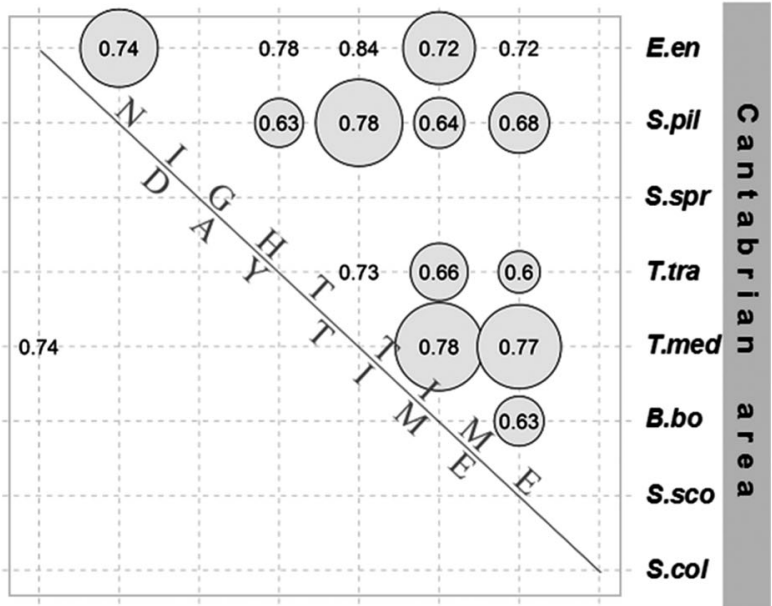

E.en S.pil S.spr T.tra T.med B.bo S.sco S.col

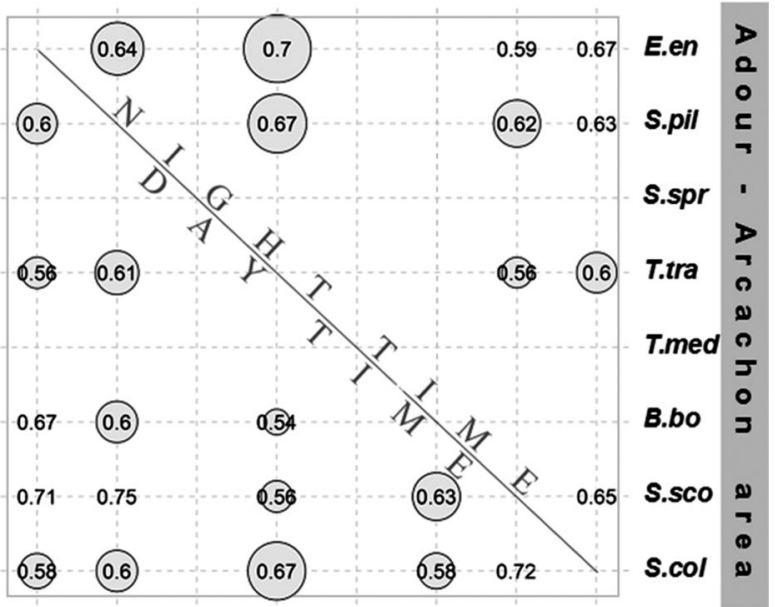

E.en S.pil S.spr T.tra T.med B.bo S.sco S.col

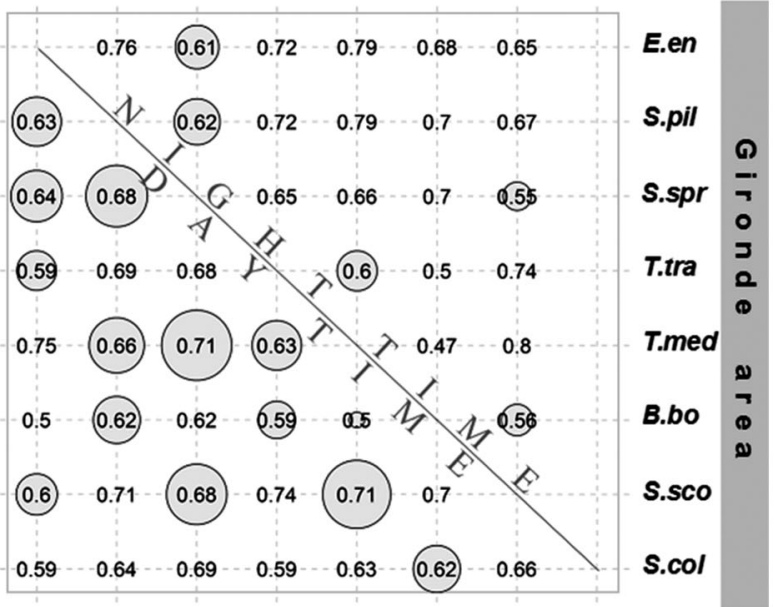

E.en S.pil S.spr T.tra T.med B.bo S.sco S.col

Fig. 8. Pairwise comparisons of the Pianka index $(O)$ between predator species in each geographical area, plotted as contingency diagrams. Indexes are indicated with numbers, and those comparisons that showed significant difference, i.e. $\mathrm{p}$ (observed $\leq$ expected) $<0.05$ include a circle, with size proportional to the index value. Diagrams on the left side are divided by season, bottom-left parts of the diagrams showing spring data and top-right parts showing autumn data. On the right side, diagrams are divided by the sampling time range, daytime on the bottom-left side and nighttime on the top-right side. E.en: Engraulis encrasicolus; S.pil: Sardina pilchardus; S.spr: Sprattus spratus; T.tra: Trachurus trachurus; T.med: T. mediterraneus; 
(Espinoza \& Bertrand 2008, Nikolioudakis et al. 2014). Accordingly, our results show the prey biomass composition based on length-weight conversion equations applied to direct length measurements and counts of prey species at a low taxonomic level. This way, the underestimation of the ingested biomass due to ingestion of the smallest fraction (phytoplankton and micro-zooplankton) is assumed to be low, relative to the biomass calculated from the analyzed prey size range.

The present study is based on opportunity-based surveys oriented to stock assessment using different methods, and therefore, some biases on the stomach sampling were due to the trawling methodology (ICES 2011a,b). Accordingly, the following limitations should be considered:

(1) The number of samples. Both BIOMAN and PELACUS surveys have the anchovy as the target species and, since fishing stations were based on previous acoustic observations (ICES 2011a,b), that results in a more effective anchovy sampling in comparison with other species. As a result, anchovy, Atlantic and Mediterranean horse mackerel and Atlantic chub mackerel sampled in spring (BIOMAN) were all from night trawls. In contrast, all samples collected in autumn (PELACUS) were obtained during daytime.

(2) The coverage of predator vertical distribution. All trawls were made close to the surface (maximum fishing depth $=45 \mathrm{~m}$, see 'Materials and methods'), and therefore, the diet composition analysis in the present study cannot determine whether variations in the vertical distribution of the species could result in changes of the feeding behaviour. In the same way, pelagic fish populations could show differences in their vertical distribution though different seasons and time of the day (Lezama-Ochoa et al. 2014). However, the same study by Lezama-Ochoa et al. (2014) shows that most pelagic fish remain in the upper $40 \mathrm{~m}$, and therefore, the results of this study are likely to be a relatively good representation of the diet. Further, the aim of the present study was to focus on inter-specific differences in diet composition and diet overlap when fish are sharing the niche.

Since the stomach sampling was made only at stations with co-occurrence between the species and all fish were caught in the upper water column (0 to $45 \mathrm{~m}$ depth), similar prey availability is assumed for all predator species caught in the same haul. Hence, considering that all the species share the niche and therefore feed from the same food resource, inter-specific variations are assumed to be more related to the feeding behaviour of small pelagic species rather than to differences in predator-prey (e.g. spatial) distribution.

\section{Diet composition}

Comparisons between the diet composition of small pelagic species caught at the same time (i.e. same niche) show that fish size, species, geographical area, season and sampling time are the variables significantly affecting the diet composition of small pelagic fish.

In terms of prey numbers, copepods are the main prey item for all predator species, with calanoids (e.g. Centropages spp. and Temora spp.) dominating the diet composition. However, large prey, commonly less abundant, are often more valuable in terms of energy input (e.g. Nikolioudakis et al. 2014) and therefore more important to determine inter-specific differences in aspects such as the diet preference and predation efficiency. Our results show that copepods are generally the most important biomass input for fish when large prey are not ingested. This way, the smallest size range of almost all sampled species show a calanoid copepod-based diet composition (Fig. 3), probably due to their limited ability to capture large prey (Bachiller \& Irigoien 2013).

In the same way, clupeid species feed on a wide range of copepods throughout the Bay of Biscay, but it seems that, whatever the fish size is, anchovy show more effective predation on larger prey (e.g. euphausiids and decapods) than sardine or sprat, the latter feeding almost exclusively on copepods, as observed in other regions (Möllmann et al. 2004). Differences observed between anchovy and sardine coincide with previous studies, suggesting a more effective filter-feeding behaviour by sardine (Garrido et al. 2007, van der Lingen et al. 2009) in contrast with a higher active predation by anchovy (Nikolioudakis et al. 2014). Although anchovy can eat a wide range of copepods, from the smallest meso-zooplankton species (e.g. Oncaea spp. in the Adriatic Sea anchovy; Borme et al. 2009) to calanoids (Plounevez \& Champalbert 1999, Raab et al. 2011), sardine has the ability to retain even smaller prey size fractions (e.g. phytoplankton is efficiently filtered by sardine but not by anchovy; Garrido et al. 2007, Nikolioudakis et al. 2014). However, a more efficient filtering apparatus (Nikolioudakis et al. 2014) does not necessarily mean an exclusive copepod-based diet composition. In fact, sardine also incorporate decapods, appendicularians and fish eggs into their diet when they are available (Figs. 2 \& 3).

Atlantic and Mediterranean horse mackerel seem to feed on large prey (e.g. euphausiids) more often than the other predator species (Dahl \& Kirkegaard 1986, Olaso et al. 1999, Cabral \& Murta 2002, Garrido 
\& Murta 2011), although they also show high frequencies of copepods in their diet. In terms of biomass, calanoid copepods are the most important in their diet only when large prey were not ingested (e.g. Gironde area in autumn, especially in $<130 \mathrm{~mm}$ fish; Fig. 3). However, there is not any clear trend of prey preference by fish size between areas or time. In fact, the smallest Mediterranean horse mackerel is the only species obtaining the main biomass input from the predation on euphausiids (Fig. 3). The results suggest a similar diet composition and feeding behaviour between the Mediterranean and Atlantic horse mackerel, both species showing an active predation on large prey at any time, i.e. whenever large prey are available for them (Fig. 4). Previous studies observed a greater feeding activity during daytime (Dahl \& Kirkegaard 1986), suggesting a more effective predation efficiency on euphausiids, decapods and amphipods (Cabral \& Murta 2002) under light conditions, in which visibility limitations are lower (Aksnes \& Utne 1997). However, in our study, we often observe effective predation not only during daytime but also during nighttime, such as in the case of Atlantic and Mediterranean horse mackerel (Fig. 2). This could indicate that horse mackerel feeding close to the surface can effectively predate on macrozooplankton, which are more concentrated in shallow waters during nighttime (daily vertical migration; Maycas et al. 1999). When euphausiids do not dominate the diet, most of the biomass is obtained from copepods, in contrast with previous observations in other areas where copepods are rarely ingested (e.g. Portuguese waters; Garrido \& Murta 2011).

Moreover, the biomass input in the diet of bogue both during day- and nighttime is based on large prey such as euphausiids and amphipods, the latter more frequently ingested than by the other species. However, all kind of copepods are also important, especially for the smallest bogue. Accordingly, bogue shows a large range of prey, with a tendency to ingest large organisms (e.g. appendicularians, fish larvae, etc.) when available.

In Atlantic mackerel and Atlantic chub mackerel (especially in fish $>130 \mathrm{~mm}$ ), active predation on decapods, euphausiids and fish larvae seems to be energetically more important, in accordance with previous studies (e.g. Darbyson et al. 2003, Cabral \& Murta 2002). Mysids were a special case appearing as one of the most valuable target prey only for Atlantic chub mackerel in some areas. Euphausiids and other large prey are also frequently observed not only in the Bay of Biscay (Lucio 1997, this study) but also in other areas (Castro 1993, Cabral \& Murta 2002,
Darbyson et al. 2003, Olaso et al. 2005, Langøy et al. 2012). Relative differences in prey numbers between Atlantic and chub mackerel are low, indicating that both species share the niche by feeding on the same resource and exhibiting similar feeding behaviour.

\section{Feeding intensity and feeding incidence}

Differences in the stomach-filling degree are greater between areas and times than between the species, although clupeids seem to show a lower range of variability. This pattern indicates that food availability plays a more important role in the diet than the differences between fish species, or in other words that all species have sufficient behavioural flexibility to adapt to the different conditions.

Similarly, the feeding incidence does not show any clear difference between areas or time. In general, the number of empty stomachs in our sampled fish is low, with Atlantic and Mediterranean horse mackerel as the species showing the highest percentage of empty stomachs. This predation failure happens especially at night, when capturing large prey can be more difficult for fish due to visibility limitations (Aksnes \& Utne 1997).

\section{Species richness and diversity-based trophic niche breadth}

In general, both prey richness and diversity values are higher in the gut contents of fish caught in the Adour-Arcachon and Gironde areas, where zooplankton concentration and diversity has also been found to be relatively higher than in the Cantabrian Sea (Albaina \& Irigoien 2007).

In the case of clupeids, incorporating larger prey into their diet when they grow in size could explain the increasing trend (significant for anchovy and sprat) of the diet diversity. Such a result could be even clearer if the smallest fraction of prey (i.e. phytoplankton and micro-zooplankton) would have been considered, e.g. in sardine (Garrido et al. 2007, Nikolioudakis et al. 2014). In contrast, larger predators like Atlantic horse mackerel, bogue and Atlantic mackerel decreased the diversity-based trophic niche breadth with increasing body size, which could indicate some kind of diet specialization, feeding on larger and less diverse target prey groups (e.g. euphausiids and decapods) as the predators become larger in size and more effective in catching large prey. Nevertheless, when considering all the species 
together, there was no significant relationship between fish size and trophic niche breadth. This result could also be related to the ability by all predators to use the whole prey size range at any size (Bachiller \& Irigoien 2013), area or time. For example, horse mackerel, bogue and mackerel show lower diversity at night, when large prey are the main biomass input to the diet in some areas.

\section{Diet overlap}

As shown in similar studies (Raab et al. 2011), the diet overlap is large among the 3 clupeid species, i.e. anchovy, sardine and sprat, at any time, area and season. However, it seems clear that the relatively small clupeids can also show a substantial diet overlap with larger fish like Atlantic horse mackerel, Atlantic mackerel or bogue. These larger fish can also have a relatively large diet overlap between them at the same time. Interestingly, in some cases, overlap between close species (Atlantic horse mackerel vs. Mediterranean horse mackerel; Atlantic mackerel vs. Atlantic chub mackerel) can be lower than the overlap observed when comparing one of them to other species (e.g. anchovy vs. Mediterranean horse mackerel in the Cantabrian area during spring; anchovy vs. Atlantic chub mackerel in AdourArcachon area during autumn). In fact, Pianka index values do not show a large variability between fish pairs, which suggests that differences are rather due to differences in the zooplankton composition. Overlap values seem to be determined more by food availability than by feeding selection or predator specialization. For example, in the Gironde area, individual differences in predation success on large prey during nighttime could explain relatively lower overlap indices than during daytime, when all the sampled predators seem to use a wider prey size range (i.e. from copepods to euphausiids).

In conclusion, there is evidence of a relatively large diet overlap among small pelagic species in the Bay of Biscay, especially between clupeids but also between clupeids and larger predators. The overlap is probably due to the fact that the examined pelagic fishes are more or less generalists and predate on the most available prey at any given time and area. Furthermore, although larger fish widen their prey size spectrum, incorporating larger prey, which are at the same time energetically more valuable, small prey continues to be an important component of their diet (Bachiller \& Irigoien 2013). As a result, there is an important diet overlap not only between species but also between size ranges. Top-down control of zooplankton by these planktivorous fishes (Checkley et al. 2009) suggests that changes in plankton availability for fish could result in competition for the resource and enhance the effects of intraguild predation (Irigoien \& De Roos 2011, Bachiller et al. 2015). However, the resource considered (i.e. the whole prey size range) may not be so scarce as to be limiting for overlapping species (Holbrook \& Schmitt 1989, Raab et al. 2011). In that case, even a complete diet overlap may not involve competition (Hurlbert 1978, Holt 1987). A complete evaluation of competition will require quantifying different fish and plankton species abundance in each area to estimate whether feeding can be limited by the abundance of different prey items. Equally, fish eggs and fish larvae appear frequently in the diet of most species, suggesting that intraguild predation can play a significant role (e.g. Bachiller et al. 2015) to shape the whole community. But again, to estimate its impact requires simultaneous estimates of the different fish species biomass in each of the areas.

In any case, in terms of an ecosystem approach to fisheries management, it is important to take into account that in the Bay of Biscay there is a high level of diet overlap not only between clupeids but also among small pelagic fish in general. Further research on aspects such as fish abundance, plankton consumption estimations and spatial overlap would therefore be of great interest to better understand ecological implications of the variation in feeding activity among small pelagic fish species.

Acknowledgements. This research was supported by the ECOANCHOA project promoted by the Department of Agriculture, Fisheries and Food of the Basque Country Government and by the EU FP7 FACTS (Forage Fish Interactions) project, Grant Agreement No. 244966. E.B. was supported by a doctoral fellowship (2007-2011) from the Iñaki Goenaga Zentru Teknologikoen Fundazioa (IG-ZTF) and by a postdoctoral fellowship (2014-2016) from the Department of Education, Language policy and Culture - Basque Country Government (EJ-GV). This is contribution no. 718 from AZTI-Tecnalia (Marine Research Division).

\section{LITERATURE CITED}

Aksnes DL, Utne ACW (1997) A revised model of visual range in fish. Sarsia 82:137-147

Albaina A, Irigoien X (2007) Zooplankton communities and oceanographic structures in a high-resolution grid in the south-eastern corner of the Bay of Biscay. Estuar Coast Shelf Sci 75:433-446

Alheit J, Roy C, Kifani S (2009) Decadal-scale variability in populations. In: Checkley D, Alheit J, Oozeki Y, Roy C (eds) Climate change and small pelagic fish. Cambridge 
University Press, Cambridge, p 67-87

Bacha M, Amara R (2009) Spatial, temporal and ontogenetic variation in diet of anchovy (Engraulis encrasicolus) on the Algerian coast (SW Mediterranean). Estuar Coast Shelf Sci 85:257-264

Bachiller E, Irigoien X (2013) Allometric relations and consequences for feeding in small pelagic fish in the Bay of Biscay. ICES J Mar Sci 70:232-243

Bachiller E, Fernandes JA, Irigoien X (2012) Improving semiautomated zooplankton classification using an internal control and different imaging devices. Limnol Oceanogr Methods 10:1-9

> Bachiller E, Cotano U, Boyra G, Irigoien X (2013) Spatial distribution of the stomach weights of juvenile anchovy (Engraulis encrasicolus L.) in the Bay of Biscay. ICES J Mar Sci 70:362-378

Bachiller E, Cotano U, Ibaibarriaga L, Santos M, Irigoien X (2015) Intraguild predation between small pelagic fish in the Bay of Biscay: impact on anchovy (Engraulis encrasicolus L.) egg mortality. Mar Biol 162:1351-1369

> Bergeron JP (2009) Nutritional condition of anchovy Engraulis encrasicolus larvae in connection with mesozooplankton feeding catabolism in the southern Bay of Biscay, NE Atlantic. J Exp Mar Biol Ecol 377:76-83

Borme D, Tirelli V, Brandt SB, Umani SF, Arneri E (2009) Diet of Engraulis encrasicolus in the northern Adriatic Sea (Mediterranean): ontogenetic changes and feeding selectivity. Mar Ecol Prog Ser 392:193-209

Cabral HN, Murta AG (2002) The diet of blue whiting, hake, horse mackerel and mackerel off Portugal. J Appl Ichthyology 18:14-23

Castro JJ (1993) Feeding ecology of chub mackerel Scomber japonicus in the Canary islands area. S Afr J Mar Sci 13: $37-41$

Checkley J, Alheit J, Oozeki Y, Roy C (eds) (2009) Climate change and small pelagic fish. Cambridge University Press, Cambridge

Conway DVP, Coombs SH, Fernández de Puelles ML, Tranter PRG (1994) Feeding of larval sardine, Sardina pilchardus (Walbaum), off the north coast of Spain. Bol Inst Esp Oceanogr 10:165-175

Costalago D, Palomera I (2014) Feeding of European pilchard (Sardina pilchardus) in the northwestern Mediterranean: from late larvae to adults. Sci Mar 78:41-54

Costello MJ (1990) Predator feeding strategy and prey importance: a new graphical analysis. J Fish Biol 36: 261-263

> Cotano U, Irigoien X, Etxebeste E, Alvarez P, Zarauz L, Mader J, Ferrer L (2008) Distribution, growth and survival of anchovy larvae (Engraulis encrasicolus L.) in relation to hydrodynamic and trophic environment in the Bay of Biscay. J Plankton Res 30:467-481

Dahl K, Kirkegaard E (1986) Stomach contents of mackerel, horse mackerel and whiting in the Eastern part of the North Sea in July 1985. ICES J Mar Sci 68:1-18

> Darbyson E, Swain DP, Chabot D, Castonguay M (2003) Diel variation in feeding rate and prey composition of herring and mackerel in the southern Gulf of St Lawrence. J Fish Biol 63:1235-1257

Entsminger GL (2014) EcoSim Professional: null modeling software for ecologists, Version 1. Acquired Intelligence, Kesey-Bear \& Pinyon Publishing, Montrose, CO. www. garyentsminger.com/ecosim/index.htm

Espinoza P, Bertrand A (2008) Revisiting Peruvian anchovy (Engraulis ringens) trophodynamics provides a new vision of the Humboldt Current system. Prog Oceanogr 79:215-227

Estes JA, Terborgh J, Brashares JS, Power ME and others (2011) Trophic downgrading of planet Earth. Science 333:301-306

Garrido S, Murta AG (2011) Interdecadal and spatial variations of diet composition in horse mackerel Trachurus trachurus. J Fish Biol 79:2034-2042

Garrido S, Marçalo A, Zwolinski J, van der Lingen CD (2007) Laboratory investigations on the effect of prey size and concentration on the feeding behaviour of Sardina pilchardus. Mar Ecol Prog Ser 330:189-199

Garrido S, Ben-Hamadou R, Oliveira PB, Cunha ME, Alexandra Chícharo M, van der Lingen CD (2008) Diet and feeding intensity of sardine Sardina pilchardus: correlation with satellite-derived chlorophyll data. Mar Ecol Prog Ser 354:245-256

Harris RP, Wiebe PH, Lenz J, Skjoldal HR, Huntley M (eds) (2000) ICES zooplankton methodology manual. Academic Press, San Diego, CA

Holbrook SJ, Schmitt RJ (1989) Resource overlap, prey dynamics, and the strength of competition. Ecology 70 : 1943-1953

Holt RD (1987) On the relation between niche overlap and competition: the effect of incommensurable niche dimensions. Oikos 48:110-114

Hurlbert SH (1978) The measurement of niche overlap and some relatives. Ecology 59:67-77

Hyslop EJ (1980) Stomach contents analysis - a review of methods and their application. J Fish Biol 17:411-429

ICES (2011a) Report of the working group on widely distributed stocks (WGWIDE). 23-29 August, ICES CM 2011/ ACOM:15. ICES Headquarters, Copenhagen

ICES (2011b) Report of the working group on anchovy and sardine (WGANSA). 24-28 June, Vigo, Spain. ICES CM 2011/ACOM:16

> Irigoien X, De Roos A (2011) The role of intraguild predation in the population dynamics of small pelagic fish. Mar Biol 158:1683-1690

Irigoien X, Cotano U, Boyra G, Santos M and others (2008) From egg to juvenile in the Bay of Biscay: spatial patterns of anchovy (Engraulis encrasicolus) recruitment in a nonupwelling region. Fish Oceanogr 17:446-462

Ivlev VS (ed) (1961) Experimental ecology of the feeding of fishes. Yale University Press, New Haven, CT

Koutsikopoulos C, Le Cann B (1996) Physical processes and hydrological structures related to the Bay of Biscay anchovy. In: Palomera I, Rubiés P (eds) The European anchovy and its environment. Scientia Marina, Consejo Superior de Investigaciones Científicas (CSIC), Barcelona, p 9-19

> Langøy H, Nøttestad L, Skaret G, Broms C, Fernö A (2012) Overlap in distribution and diets of Atlantic mackerel (Scomber scombrus), Norwegian spring-spawning herring (Clupea harengus) and blue whiting (Micromesistius poutassou) in the Norwegian Sea during late summer. Mar Biol Res 8:442-460

Lawlor LR (1980) Structure and stability in natural and randomly constructed competitive communities. Am Nat 116:394-408

> Lezama-Ochoa A, Irigoien X, Chaigneau A, Quiroz Z, Lebourges-Dhaussy A, Bertrand A (2014) Acoustics reveals the presence of a macrozooplankton biocline in the Bay of Biscay in response to hydrological conditions and predator-prey relationships. PLoS ONE 9:e88054 
Lucio P (1997) Biological aspects of mackerel (Scomber scombrus L. 1758) in the Bay of Biscay from the Basque country catches in the period 1987-1993. ICES CM/1997 BB:9

Maycas ER, Bourdillon A, Macquart-Moulin C, Passelaigue F, Patriti G (1999) Diel variations of the bathymetric distribution of zooplankton groups and biomass in CapFerret Canyon, France. Deep-Sea Res II 46:2081-2099

Möllmann C, Kornilovs G, Fetter M, Köster FW (2004) Feeding ecology of central Baltic Sea herring and sprat. J Fish Biol 65:1563-1581

Munuera Fernández I, González-Quirós R (2006) Analysis of feeding of Sardina pilchardus (Walbaum, 1792) larval stages in the central Cantabrian Sea. Sci Mar 70:131-139

Nikolioudakis N, Isari S, Pitta P, Somarakis S (2012) Diet of sardine Sardina pilchardus: an 'end-to-end' field study. Mar Ecol Prog Ser 453:173-188

Nikolioudakis N, Isari S, Somarakis S (2014) Trophodynamics of anchovy in a non-upwelling system: direct comparison with sardine. Mar Ecol Prog Ser 500:215-229

Olaso I, Cendrero O, Abaunza P (1999) The diet of the horse mackerel, Trachurus trachurus (Linnaeus, 1758), in the Cantabrian Sea (north of Spain). J Appl Ichthyol 15:193-198

Olaso I, Gutiérrez-Zabala JL, Villamor B, Carrera P, Valdés L, Abaunza P (2005) Seasonal changes in the northeastern Atlantic mackerel diet (Scomber scombrus) in the north of Spain (ICES Division VIIIC). Mar Biol Assoc UK 85:415-418

Pikitch EK, Rountos KJ, Essington TE, Santora C and others (2014) The global contribution of forage fish to marine fisheries and ecosystems. Fish Fish 15:43-64

Plounevez S, Champalbert G (1999) Feeding behaviour and trophic environment of Engraulis encrasicolus (L.) in the Bay of Biscay. Estuar Coast Shelf Sci 49:177-191

R Development Core Team (2014) R: a language and environment for statistical computing. $\mathrm{R}$ Foundation for Statistical Computing, Vienna

Raab K, Nagelkerke LAJ, Boerée C, Rijnsdorp AD, Temming A, Dickey-Collas M (2011) Anchovy Engraulis encrasicolus diet in the North and Baltic Seas. J Sea Res 65:131-140

Editorial responsibility: Charles Birkeland, Honolulu, Hawaii, USA
Scharf FS, Juanes F, Rountree RA (2000) Predator size-prey size relationships of marine fish predators: interspecific variation and effects of ontogeny and body size on trophic-niche breadth. Mar Ecol Prog Ser 208:229-248

Smith PE, Flerx W, Hewitt RH (1985) The CalCOFI vertical egg tow (CalVET) net. In: Lasker R (ed) An egg production method for estimating spawning biomass of pelagic fish: application to the northern anchovy, Engraulis mordax. Dept of Commerce, Washington, DC

Strauss RE (1979) Reliability estimates for Ivlev's electivity index, the forage ratio, and a proposed linear index of food selection. Trans Am Fish Soc 108:344-352

Utne KR, Huse G, Ottersen G, Holst JC and others (2012) Horizontal distribution and overlap of planktivorous fish stocks in the Norwegian Sea during summers 19952006. Mar Biol Res 8:420-441

> van der Lingen CD, Hutchings L, Field JG (2006) Comparative trophodynamics of anchovy Engraulis encrasicolus and sardine Sardinops sagax in the southern Benguela: Are species alternations between small pelagic fish trophodynamically mediated? Afr J Mar Sci 28:465-477

van der Lingen $C D$, Bertrand A, Bode A, Brodeur RD and others (2009) Trophic dynamics. In: Checkley J, Alheit J, Oozeki Y, Roy C (eds) Climate change and small pelagic fish. Cambridge University Press, Cambridge, p 112-157

Varela M, Larreñaga A, Costas E, Rodríguez B (1988) Contenido estomacal de la sardina (Sardina pilchardus, Walbaum) durante la campaña Saracus 871 en las plataformas Cantábrica y de Galicia en Febrero de 1987. Bol Inst Esp Oceanogr 5:17-28

Varela M, Alvarez-Ossorio MT, Valdés L (1990) Método para el estudio cuantitativo del contenido estomacal de la sardina. Resultados preliminares. Bol Inst Esp Oceanogr 6:117-126

Wickham H (2009) ggplot2: elegant graphics for data analysis. Springer, New York, NY

Wiebe PH, Benfield MC (2003) From the Hensen net toward four-dimensional biological oceanography. Prog Oceanogr 56:7-136

Submitted: December 11, 2014; Accepted: July 27, 2015

Proofs received from author(s): August 3, 2015 